CORRECTION

\title{
Correction: The effect of light wavelength on in vitro bilirubin photodegradation and photoisomer production
}

Hendrik J. Vreman ${ }^{1}$, Stephanie Kourula ${ }^{1}$, Jana Jašprová ${ }^{2}$, Lucie Ludvíková ${ }^{3}$, Petr Klán ${ }^{3}$, Lucie Muchová ${ }^{2}$, Libor Vítek² ${ }^{2}$ Benjamin K. Cline ${ }^{1}$, Ronald J. Wong ${ }^{1}$ and David K. Stevenson ${ }^{1}$

Pediatric Research (2019) 85:905; https://doi.org/10.1038/s41390-019-0356-1

Correction to: Pediatric Research https://doi.org/10.1038/s41390019-0310-2, published online: 26 January 2019

Following publication of this article, the authors noticed that an incorrect affiliation was assigned to the author "Lucie Muchová".
The original article has now been updated so that the author "Lucie Muchová" is associated with the "Institute of Medical Biochemistry and Laboratory Diagnostics, 1st Faculty of Medicine, Charles University, Kateřinská 32, 12000 Prague, Czech Republic". This has been corrected in both the PDF and HTML versions of the article.

\footnotetext{
${ }^{1}$ Department of Pediatrics, Stanford University School of Medicine, 300 Pasteur Drive, Room S214, Stanford, CA 94305, USA; ${ }^{2}$ Institute of Medical Biochemistry and Laboratory

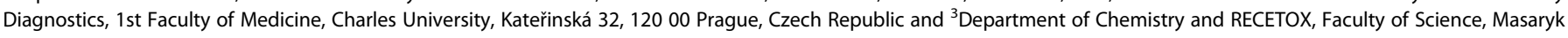
University, Kamenice 5, 62500 Brno, Czech Republic

Correspondence: Hendrik J. Vreman (henk.vreman@stanford.edu) or Libor Vítek (vitek@cesnet.cz)

Shared first authors: Hendrik J. Vreman, Stephanie Kourula, Jana Jašprová
}

Published online: 27 February 2019 